\title{
Comparing crime reporting factors in EU countries
}

\author{
Diego Torrente ${ }^{1}$. \\ Pedro Gallo ${ }^{1}$. \\ Christian Oltra ${ }^{1}$
}

\begin{abstract}
Through crime-reporting citizens make their security needs explicit to the police. This information helps the police in the allocation of resources. In the European Union, there are significant differences among countries, both in terms of overall and specific crime-reporting rates. Factors highlighted by the literature that might explain these differences are not entirely satisfactory. There is little comparative research, and most published studies are nation-centred, based on the experience of central and northern European countries, and largely focused on the situational variables related to the criminal incident itself. It is widely assumed that situational variables have a universal explanatory capacity in crime reporting. This article questions this assumption and shows that a number of factors weight differently in explaining national rates. Following a literature review, we identified four groups of causal factors and analysed their explanatory capacity. These are related largely to the incident (rational models) and victims' perception (psychological models). In addition, we also analysed the influence of institutional and community factors. The European Survey on Crime and Safety database was used for our analysis. Results show the existence of two areas in Europe, the northcentral area and the south-eastern area, in terms of crime reporting rates and the factors that explain these differences. Rational and psychological models explain crime-reporting practices better in the north-central area. In contrast, socio-demographic variables and social inequalities are more relevant for explaining crime reporting in the south-eastern area of Europe. Institutional variables are also important in eastern countries. Community factors are not significant explanatory variables due to the limitations of indicators available in the database. Our research reveals that crime-reporting is a rather more complex phenomenon than is often assumed, and highlights the limitations of existing knowledge and methodologies on comparative crime-reporting.
\end{abstract}

\section{Keywords}

Crime reporting . Crime-reporting factors . Demand for security. European countries . Police

\begin{abstract}
This research has been supported by the Spanish Plan Nacional de la Ciencia (2012-14). The research team comprises Diego Torrente, Pedro Gallo, Oscar Jaime, Cristina Rechea, and Juli Sabaté. Vanessa Peñaranda, and Tamara Rubiños have also collaborated. Santiago Pérez-Hoyos has carried out the statistics tasks. We would like to thank Marga Mari-Klose for her valuable comments and suggestions. Preliminary versions of this article have been presented at the 109th Annual Meeting of the American Sociological Association, and the XI Congreso Español de Sociología. The article was completed at the European University Institute.
\end{abstract}




\section{Topic and relevance}

The legitimacy of any State depends largely on its success in ensuring the safety and welfare of its citizens. Public safety and crime control are central concerns of democratic governments, particularly in a context of rapid change with regard to security issues and population demands (Thomé and Torrente 2003). Traditionally, crime reporting has been analysed as a relevant aspect in the performance of criminal justice systems. More recently, it has also been considered as an important indicator of institutional development. Soares (2004b) argues that countries with higher reporting rates are also those with the best governance performance indicators. As crime affects important aspects of people's lives, their property and their rights, the degree of response to it becomes an indicator of trust in institutions and even of good democratic health (Soares 2004b).

The police forces hold a central role in the management of public security despite not being the only actor. However, the police depend heavily on public information for both ascertaining criminal reality and providing effective responses to it (Torrente 2001). Crime reporting is the formal act by which citizens communicate incidents and mobilize police services. Through it, the police become aware of problems and are able to direct their actions (Reiss 1971; Baumer and Lauritsen 2010). Without it, the police mandate becomes distorted and budgets, resources and policies are not correctly oriented, putting the effectiveness and legitimacy of the institution at risk. Despite this, according to international victimization surveys, the population reports between a third and a half of all ordinary crimes suffered annually (Van Dijk and Mayhew 1992; Van Dijk et al. 2005). These data indicate that the police are disconnected from a significant part of reality. The consequences of this can be particularly serious if social inequality appears associated to demand differences. In this case, certain vulnerable groups may be excluded from security.

It should be noted that the demand for security from the police is a complex phenomenon, and not always channelled through crime reporting alone. The population also requires information, advice, prevention, mediation and other security services that are not usually channelled through a formal report. The police may also use information for preventing crime, carry out criminal intelligence tasks or other concerns. Studies show that most police time is spent maintaining order, providing services and prevention, rather than on criminal law enforcement (Bercal 1970).

According to international surveys, culturally different countries such as Portugal, Poland and Japan have similar crime reporting rates (Bouten et al. 2003). In addition, geographically close countries like The Netherlands and Germany, or Sweden and Finland, show meaningful differences in reporting rates. Reporting crimes should therefore be understood as a complex phenomenon that goes beyond the occurrence of particular incidents or individual victimiza-tion (Sabaté 2005). Differences between countries are linked to crime patterns, but also to other social factors that are less well known. There is the need for more comparative research to account for these differences. Indeed, most available studies have a local or national focus; they refer to central or northern European realities, and places emphasis mainly on the factors 
surrounding the criminal incident itself. These sources of "bias" limit our understanding of crime reporting. By comparing a wide range of European countries, and adopting a theoretically inclusive analytical model, our research aims at contributing to a better understanding of national and regional differences in crime reporting, as well as of the factors that explain these differences.

\section{Theoretical framework}

This section aims at, first, providing an overview of research on crime-reporting factors and, second, discussing key methodological issues on the topic. In the 1970s, the spread of crime victim surveys showed that a significant amount of crime incidents were not reported to the police (Skogan 1984). This has led to an increased interest in the study of factors influencing crime reporting. In reviewing these contributions, we can tell apart four major theoretical paradigms according to Goudriaan et al. typology (2005): rational (Skogan 1984; Gottfredson and Hinderland 1979; Laub 1981), psychological (Jaehnig et al. 1981), institutional (Tolsma et al. 2012) and community models (Goudriaan et al. 2004; Bouten et al. 2003). In addition, we have identified in the literature a number of socio-demographic attributes of the victim that are claimed to be of importance (Skogan 1984; Tarling and Morris 2010; Conaway and Lohr 1994). Although in some case there are contradictory results, women are slightly more likely to report crimes than men (Green 1981), and older people report more often than young people (Van Dijk and Steinmetz 1980). White and indigenous communities report more frequently than immigrants and ethnic minorities (Skogan 1981), house owners more than non-owners (Skogan 1976; Waller and Okihiro 1978), middle-income groups more than the lower and higher income groups (Baumer 2002), and those with a higher education attainment level more than those with a lower level (Fisher et al. 2003).

The rational paradigm is based on a simple idea: people report crimes if the benefits of doing so outweigh the costs. It holds an individualistic view, in which people are judged as rational actors isolated from their broader social environment. The emphasis here is placed on aspects surrounding the criminal incident itself. The predominant individualistic perspective on criminal justice systems fosters this view. Thus, the main aspect defended by this approach is the balance between the benefits and costs in a rational choice situation.

Benefits and costs, however, can be very diverse (economic, psychological, time related, relational). The benefits of reporting can be expressed in terms of retrieving the lost object, receiving compensation from an insurance company, satisfying the desire to punish the perpetrators, preventing a second attack, or attracting police attention. The costs are measured in terms of loss of time, inconvenience, secondary victimization or other emotional costs. The final balance between them is what matters. For this reason, a large number of studies show the seriousness of the offense as the most determining factor in making a rational decision (Gottfredson and Hinderland 1979; Skogan 1976, 1984; Sparks et al. 1977). Crime severity can be expressed in terms of the use of a weapon, force, injuries caused, economic loss or intrusion of privacy, among others. The most serious crimes are reported more often because the expected benefits outweigh the costs of time, money and other inconveniences. From this perspective, the type of crime is relevant in explaining crime-reporting practices because it involves a certain magnitude of damage (Mayhew 1993; Laub 1981). Insurance coverage has been pointed as an important factor in reporting property crimes (Van Dijk et al. 2005). However, it is more relevant at an individual level than it is at a national level (Goudriaan et al. 2004) 
Under the rational view, the type of relationship between the victim and the perpetrator influences the cost-benefit balance, too. In general terms, conflicts between known people, or within families, are less reported than those between strangers (Felson et al. 1999, 2002; Reyns and Englebrecht 2010). Relational distance is therefore decisive. Rational calculation is determined by the degree of dependence, the desire to continue living together, the costs of crime reporting in relational terms and, in some cases, fear of the aggressor's reactions. However, there is evidence of a growth in prosecution among relatives and prosecution linked to greater gender equality within the family, and the weakening of ties and commitments at work or within associations (Tarling and Morris 2010).

The rational model, although explaining much of the statistical variance in individual reporting practices, has important limitations (Goudriaan et al. 2004). The costs and benefits of crime reporting depend largely on how they are perceived by the victims, making it more a subjective matter than an objective one. Moreover, victims' evaluations can be affected by other factors such as their immediate social network (family, friends and neighbours), the pressures of a particular group or organization, legal norms or other social values. The mechanism that people use to balance costs and benefits (which are mixed in real life) is not entirely clear. The rational model does not take into account psychological factors but, even more important, it does not consider institutional, community or societal factors.

The second paradigm that attempts to explain crime reporting is psychological (Fisher et al. 2003). More than a homogeneous theoretical model, it comprises a set of different approaches that emphasize the psychological components present in the victim's cost-benefit analysis and in human behaviour in general. From this perspective, severity is also considered an important element although, unlike the rational perspective, its effects are of an indirect nature. The perception of severity causes an emotional response (fear, stress, perceived unfairness) that influences decisions. Likewise, if the victim knows the offender, emotional considerations are more present. Previous experiences of victimization can make victims more vulnerable on the one hand, but give them experience of previous crime reporting on the other. Multiplevictimization do not lead necessarily to more crime reporting (Carcach 1997). Fear of crime and attitudes towards life are also relevant factors (Jaehnig et al. 1981). One limitation of both psychological and rational approaches is that they place emphasis on the incident itself or on its perception by the victim (Goudriaan et al. 2004). All these micro-social factors are of little assistance in explaining the differences at the aggregate level, or among countries. Other contextual, institutional or macro-social factors may be more useful. Such factors have received increased attention in recent publications (Tolsma et al. 2012).

The third paradigm is institutional. From this perspective, crime reporting is viewed as a formal act that receives its meaning and practical implications within the institutional system of which it forms a part. Crime reporting connects the victim with the police, courts, prisons and other public services, as well as private institutions such as insurance or security companies. Crime reporting is a part of broader institutional structures such as the legal system of a country. What people expect from the system, what it really offers and the real consequences of reporting are important aspects in this respect. For example, support or protection services offered by police to victims or witnesses, on-line reporting possibilities, available policing resources, types of response given or actual and perceived effectiveness are relevant examples (Skogan 1978; Bercal 1970; Tolsma et al. 2012). There is evidence that confidence in police effectiveness plays an incentivizing role in crime reporting (Anderson 1999; Baumer 2002; Sherman 1993; Soares 2004b). When victims believe the police forces are effective, they see the benefits of filing a report more rewarding. Further, if there is a collective belief that citizens 
can trust the police, this favours reporting, too. Policing models like Community Policing can also foster crime reporting (Schnebly 2008).

Soares $(2004 a, b)$ holds the idea that the reporting of crimes is a good indicator of institutional development. Combining data from multiple sources, including UNCS and ICVS, he finds that institutional stability, the presence of the police and the corruption index of a country are all associated with reporting rates. Citizen demands and participation lead to good governance and institutional development, and these to more efficiency in the public sector, and thereafter efficiency again increases confidence in institutions. However, the existence of a connection been reporting and institutional confidence has recently been questioned (Kääriäinen and Sirén 2011).

The fourth paradigm is represented by the community model, which has received much attention in the last 20 years. It refers to the immediate social networks of victims themselves or the communities where they live. Recent research highlights the importance of the immediate environment of the victims (family, friends, colleagues and other social networks) in the decision to report a crime. Family and other social networks are important sources of opinion and advice in stressful situations (Greenberg and Ruback 1992). Organizations (a school, church, business, etc.) are also relevant because they can influence the victim's decision (Ruback et al. 1999).

Studies examining the effect of neighbourhood characteristics on reporting practices point to three main factors: social cohesion, confidence in police effectiveness and socio-economically disadvantaged neighbourhoods (Goudriaan et al. 2005; Baumer 2002). Levels of social cohesion, social capital, collective efficacy (Sampson et al. 1997) or informal control (Vélez 2001) can affect reporting rates in different directions. Cohesive communities, with more resources and social capital, effective mechanisms of informal social control or mutual support networks can reduce crime rates and also improve residents' feelings of safety. This finding is consistent with the social disorganization model established by the Chicago School (Shaw and McKay 1942). Conversely, homogeneous and well-organized communities may be more intolerant to small deviations and can be quicker to mobilize the police. However, this evidence is inconclusive.

Social stratification (unequal access to resources) and socioeconomic disadvantages have also been highlighted in the literature in relation to crime reporting (Baumer 2002). According to the classic study by Donald Black (1976), The behavior of law, the lower the status of a neighbourhood, the less use of the law. The accumulated evidence linking economic disadvantage with low reporting rates vary. Some studies find no relationship (Bennet and Weigand 1994; Gottfredson and Hinderland 1979), while others show a moderate relationship (Baumer 2002; Fishman 1979). These contradictory results have been explained. Goudriaan et al. (2005) demonstrate that social cohesion and trust in the police are intervening variables. Some studies show a connection between economic development, individualism and the level of prosecution (Tarling and Morris 2010). Baumer and Lauritsen (2010) link the increase in crime reporting in the United States since the 1970s to a greater relational distance due to income inequality, social diversity and trust.

Methodological issues are also of importance. Most of the mentioned research is based on the analysis of national cases. There is not much international comparative research on crime reporting. Longitudinal studies of changing national values over time show that national context affects crime reporting habits and rates (Goudriaan et al. 2004). National differences might therefore be relevant. However, cross-sectional studies do not lead to this conclusion because they are based on national survey data and incident related variables. Skogan (1984) reviewed several victimization surveys using different methodologies across nations, and 
argued that crime severity is the most determinant factor, and that the nation and victims characteristics have almost no effect. Bennet and Weigand (1994) compare factors between Belize and the USA. They conclude that crime-related factors are also key factors in developing countries. The appearance of international victimization surveys in the 1980s, like the ICVS, overcomes comparability biases (Van Dijk and Mayhew 1992; Van Dijk 2015). Although they show significant differences between countries, most studies do not find a national socio-cultural effect because they fail to include nation-level covariates (Kury et al. 1999); neither do they take into account the fact that respondents and crimes are clustered within nations, or control for their effect. Recently, some studies have adopted a truly international comparative perspective and, simultaneously, have incorporated socio-communitarian and institutional variables into the models. Goudriaan et al. (2004) analyse the influence of four social context variables in crime reporting: perceived competence of the police, insurance coverage, social conformity and individualism. They conclude that national contexts explain property crime reporting better than contact crime reporting. Using ICVS data and adopting an institutional view, Soares (2004b) shows that crime reporting rates across countries are strongly related to measures of institutional stability, police presence and subjective perception of corruption. These perspectives offer new insights to understand crime reporting as a social phenomenon rather than as an individual decision.

In brief, four theoretical models have been proposed to explain crime reporting. Rational models have been granted with a recognized explanatory capacity by the scientific literature; but rational and psychological models account better for individual than for large aggregates crime reporting practices. To the contrary, institutional and socio-communitarian models are more collective in nature, but are more recent in terms of their development and less tested (particularly the latter). There are no good community-related indicators in most crime victim surveys. Most available research is done at the national level, in central and northern European countries, and based on rational models. The main limitation, however, in understanding crime reporting at the national or regional level is that it leads to few truly comparative studies (Skogan 1984; Van Dijk and Mayhew 1992). Such research requires the use of large international databases using the same methodology and questionnaire in each country. When comparable data are used, two conclusions can be drawn. First, studies show significant variations in the rates of global and specific crime reporting. Second, these differences go beyond the micro aspects surrounding the criminal incident. Factors that affect aggregate crime reporting remain mostly unknown (Goudriaan et al. 2004). We need to know more about the factors affecting crime reporting when we consider countries that are diverse in criminality (echoing rational model), culture (psychological), criminal justice structures (institutional) and socio-economic reality (socio-communitarian).

\section{Objectives and hypothesis}

This research seeks to understand how the various elements influencing crime reporting vary across European countries. We seek to identify where the differences are, and whether the countries 'group up' themselves according to specific variables or not. We intend to map these variations rather than explain them. The specific objectives are:

(1) To comparatively analyse the factors explaining crime reporting in a selection of EU countries. We aim here to appraise how the different theoretical models account for national realities. 
(2) To identify country profiles in terms of similarity in crime reporting factors. In other words, we aim to establish whether countries can be grouped up according to the importance of some explanatory variables, and to make sense of these groupings.

The hypotheses to validate are:

(1) Important variations exist between countries in the weight of different factors related to crime reporting. That is, there are a number of factors acting at different levels for different countries. It is expected, for example, that rational factors, often viewed as very relevant, do not explain all national realities equally. The same can be argued for other variables. This would confirm a more complex reality of crime reporting than is often assumed in the existing literature.

(2) If explanatory factors in crime reporting are not fully universal, we can envisage certain parallelisms in factors affecting countries with similar criminality problems, criminal justice structures, and, socio-economic reality. We can also expect that similar factors will lead to similar reporting rates. So, we have hypothesized that, in countries that are alike, the rates and the factors explaining reporting behaviour may show similar patterns.

\section{Methodology}

So as to assess the relative importance of diverse types of factors in different countries, we require comparable indicators of reporting practices. The most adequate and readily available data are the European Crime and Safety Surveys (ECSS). This survey uses a questionnaire almost identical to the International Crime Victims Survey (ICVS). The ECSS were first used in 1987 and, to date, five waves of surveys have been conducted. Our research is based on the data from the 2005 wave. Unfortunately, the 2010 edition is a reduced version of the ICVS 2005, and includes only six EU countries. The survey includes, inter alia, victimization rates for ten common crimes, crime reporting, feeling of insecurity, attitudes to punishment and satisfaction with security institutions (Van Dijk et al. 2005). The fifth wave includes data from 18 countries of the European Union (Austria, Belgium, Denmark, Finland, France, Germany, Greece, Italy, Portugal, Ireland, Luxembourg, Netherlands, Sweden, UK, Estonia, Hungary, Poland and Spain). A sample of 2000 interviews was planned for each country. Countries' response rates varied from $39 \%$ (Spain) to $72 \%$ (Poland). From the original database, 14 countries were selected for analysis (21,956 records). We decided to discard the smallest countries in order to keep the number of observations similar among regions. Since we wanted to explore crime reporting, we excluded from our database those cases that did not report any crime in five years previous to the survey. The final working data set was 19,926 cases. A crime was reported to the police in 12,672 cases. Prior to the analysis, the data set was debugged and weighted to compensate sample deviation from population composition.

The research design involves two key methodological aspects. First, define how to test the fit of the different theoretical models in national realities. Second, establish an adequate criteria to classify countries in order to make sense of the results. We selected from the ECSS survey a set of indicators representing the different theoretical models reviewed above. Table 1 presents the model, and the way in which variables have been categorized for the logistic regression analysis. The dependent variable is reporting any given crime (any of the ten listed) to the police. Since we aimed at an exploratory rather than a causal analysis, for simplicity reasons 


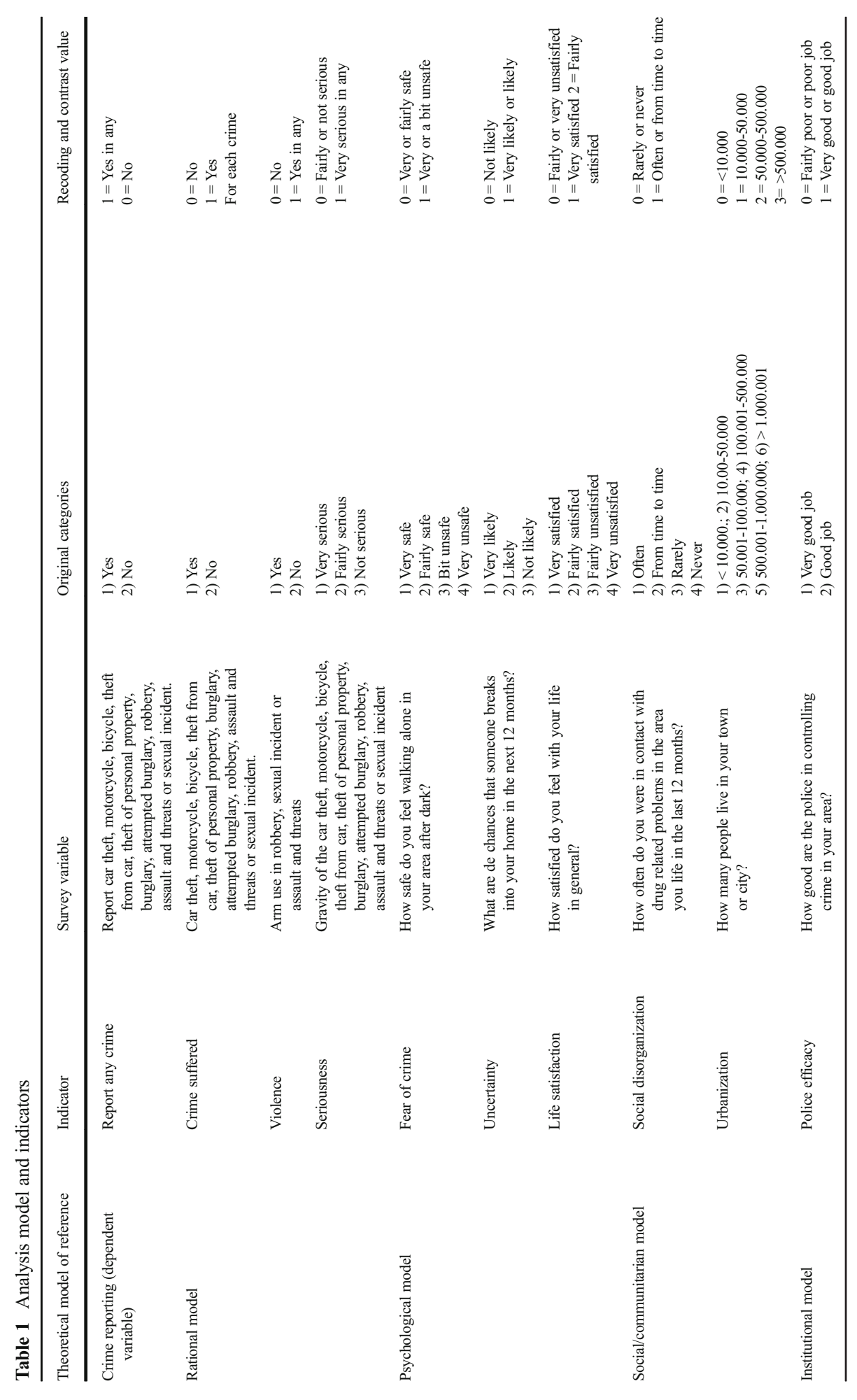




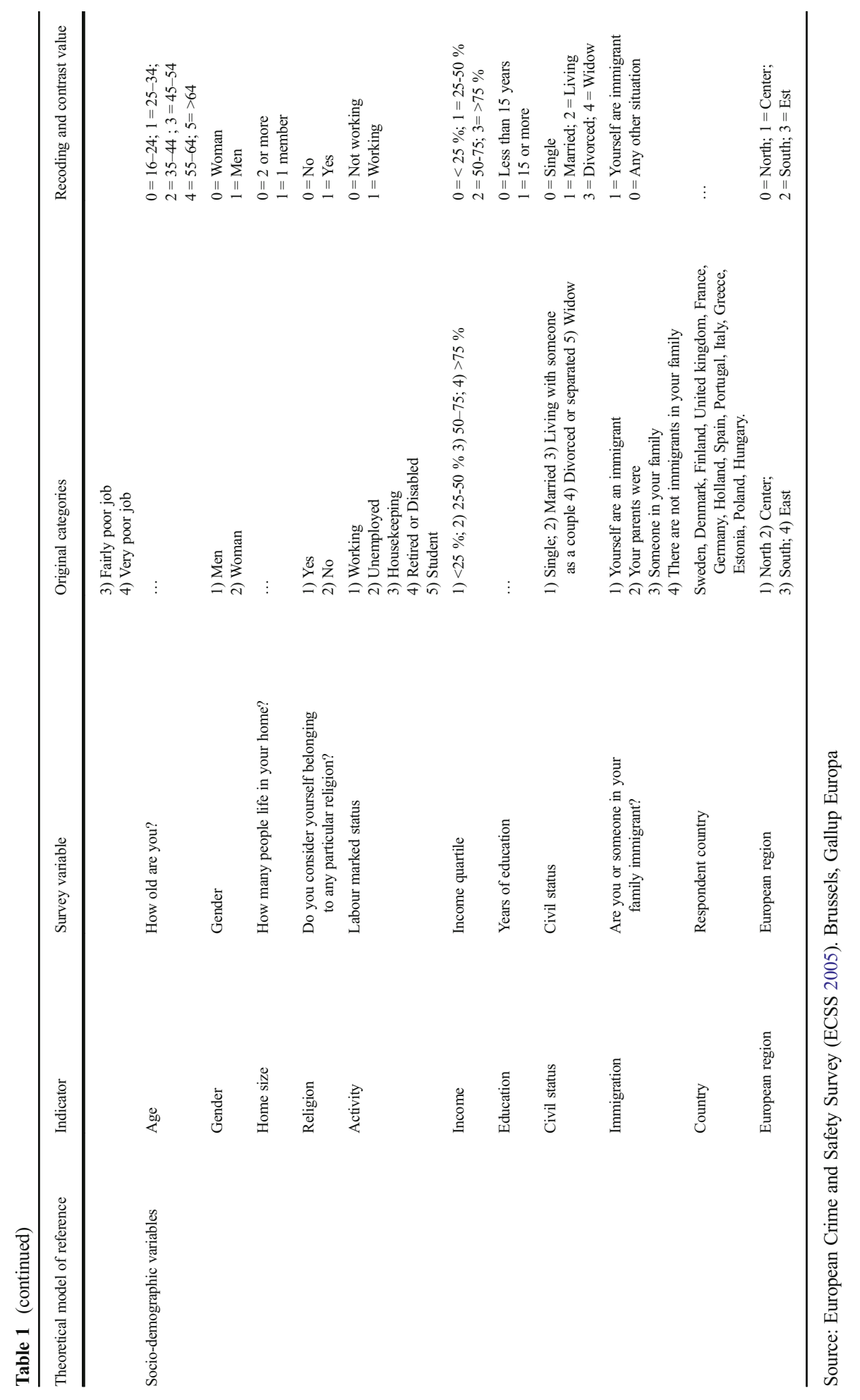


we decided to integrate property and violent (contact) crime reports (Tarling and Morris 2010; Baumer and Lauritsen 2010). The survey asks victims whether they have suffered a crime in the period 2000-2004 and, if so, to report on the last crime they were victims of.

The rational explanatory model was tested by the presence of the following variables: crime suffered (any given crime of the ten considered), degree of violence (measured by the use of weapons in the event) and severity (measured by the degree of seriousness that victims attribute to the incident). The use of weapons is intended to provide an objective element to complement the victims' subjective assessment of severity. The psychological paradigm is represented in the survey by three variables, namely, the degree of fear of crime expressed by the respondent; the belief that someone can break into your house to steal; and overall life satisfaction. As an institutional indicator, we took the respondent's perception that the police were doing a good $j o b$. This is intended to reflect the concept of police effectiveness. As indicators of the community model, we used the perception of drug-related problems in their neighbourhood, and the degree of urbanization, measured by the size of the city. Both are approaches to the concept of neighbourhood social disorganization. The survey does not provide the researcher with better alternatives. The model also includes key socio-demographic control variables that appear relevant in the literature (Skogan 1984; Tarling and Morris 2010). These variables are age, gender, household size, religion, labour marked status, income, educational level, marital status, immigration, country and European region. Although some variables included in the survey have severe limitations in capturing some of the theoretical concepts discussed, at present, there is neither a better nor a broader comparative data set available.

In order to test our model a logistic regression analysis was performed. Although our data can be considered nested (individuals nested to countries), we discarded the use of hierarchical lineal models because the number of countries selected was quite limited. To test the heterogeneity of factors acting at country level, first, a univariate logistic regression was performed for each nation in order to verify the weight of each variable separately. Then, we run a multiple $\log$ regression model, to assess the specific weight of each of these variables when others are controlled for. We repeated this analysis for each of the regions defined previously and we then looked into internal similarities and differences among them.

We hypothesized that criminally, socially and institutionally alike countries will have analogous reporting factors and rates. Accordingly, we decided to use some structural indicators to group up countries a priori and make sense of the differences found a posteriori. We avoided using latent class or latent variable methods due to the possibility of spurious aggrupation for statistical reasons. A set of national indicators (see Table 3 later on) of criminality (echoing rational and psychological model), criminal justice structure (institutional model) and socio-economic situation (socio-communitarian model) were chosen as grouping criteria. To rank them, we considered their association with the national rate of crime reporting.

\section{Crime reporting differences and countries aggrupation}

Table 2 presents the ECSS reporting rates for each crime type and country. Countries are ranked according to their global crime reporting rates. Citizens that report most to the police come from the United Kingdom, The Netherlands, Sweden and Denmark. Eastern European and Mediterranean countries appear at the bottom of the table. Northern and central European countries tend to demand more police services, while southern and eastern ones do that to a lesser degree. Variations are somewhat wider when we look at specific crimes. Property 


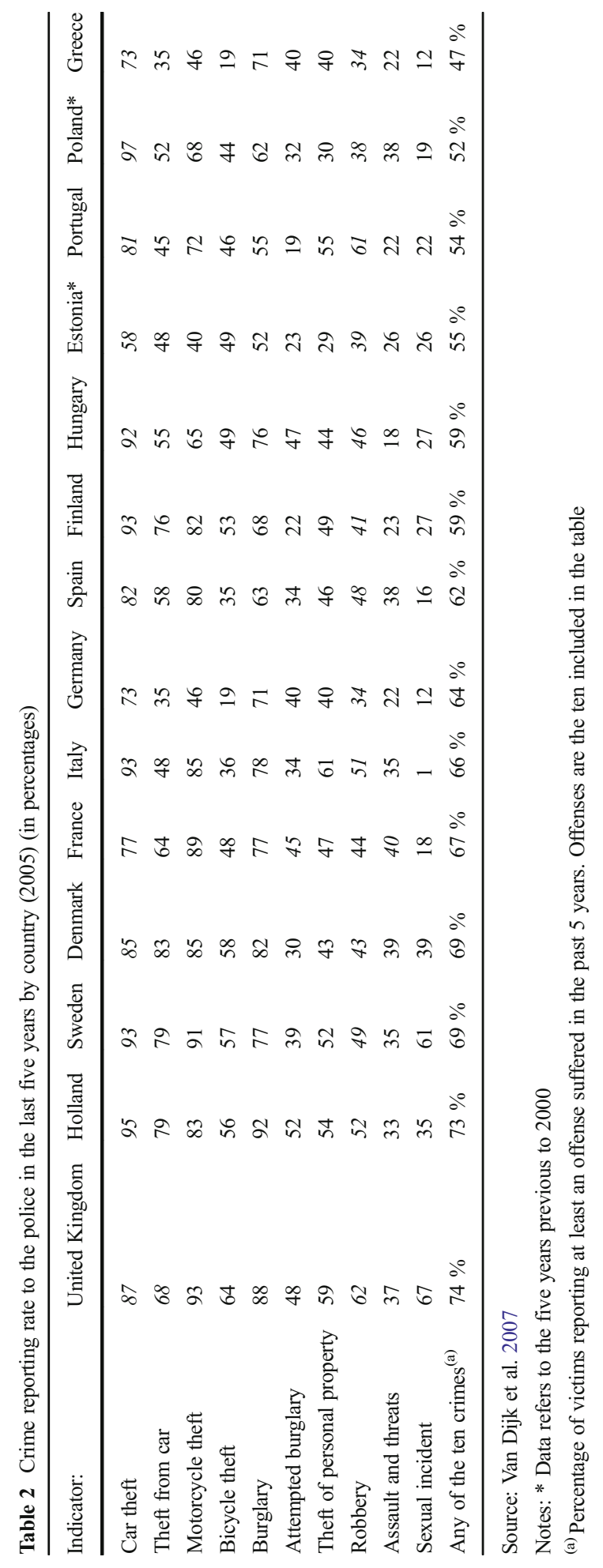


incidents tend to register higher reporting rates than violent crime in most countries, particularly in some Mediterranean and Eastern nations. Car theft is the most reported crime in almost all countries. It is also burglary and motorcycle theft, to a lesser extent. This suggests the importance of severity and economic value as factors. Countries with high global reporting figures tend to maintain higher scores in all types of property crime, but not always in violent crime. In countries with lower marks, there is more variation in property incidents and they tend to have lower figures in violent crime. Sexual incidents register the highest dispersion in figures, and car theft the lowest.

Table 3 presents ECSS aggregate crime reporting rates and some criminal, socio-economic and institutional indicators for the 14 countries included in our analysis. The purpose is to use them to group up our countries. In order to rank their relevance as a criterion, we calculate the Pearson correlation coefficient between each indicator and crime reporting figures. According to these macro indicators, crime reporting is only partially associated with crime rates and with other rational variables related to the crime event itself. Other factors are of interest, the most important of them being socio-demographic indicators such as income, unemployment, poverty and inequality. Psychological factors, such as fear, seem to also be of value in understanding crime reporting. The association between crime reporting and institutional factors is rather more complex. We rank indicators according to their correlation with reporting rates. We want to draw homogenous areas in institutional and socio economic terms. As a result, we defined four areas: The north area includes Sweden, Denmark and Finland. The central area includes the United Kingdom, France, Germany and the Netherlands. The south European area is represented by Spain, Portugal, Italy and Greece. Finally, Estonia, Poland and Hungary were grouped as the eastern European area.

\section{Results}

Raw data from Table 3 suggests that reporting rates may respond to particular socio-economic and cultural patterns. This is what Goudriaan et al. (2004: 963) call "the effects of the nationlevel context on the decision to report". Table 4 is intended to test whether the EU regions defined previously, have a distinctive effect on crime reporting rates. The table takes the northern region as a reference for comparison. The first column shows the odds ratio (OR) for each area without adjusting for other variables in the analysis. Central area countries are at the forefront in crime reporting, followed by the northern, southern and eastern regions, in this order. When adjusting for other variables in the model (second column), two clearly differentiated patterns appear. Although the number of cases decreases due to missing data, this new picture could not be fully attributed to the loss of sample size. Two major conclusions emerge from the table. First, there are significant differences in regional crime reporting rates at the regional level, both before and after adjusting the model, meaning regions have an important explanatory weight of their own. Second, in net terms, there are "two Europes" in terms of crime reporting: central and northern Europe, and southern and eastern Europe. In the latter, the likelihood of crime reporting is half that of the first. These data suggest the existence of distinctive underlying factors.

Table 5 shows the importance of each theoretical model (rational, psychological, sociocommunitarian and institutional) to explain crime reporting in each region. We decided to keep our original classification of four regions to comparatively display which factors are alike or different in each region. To this aim, we ran four separate regression models (one for each 


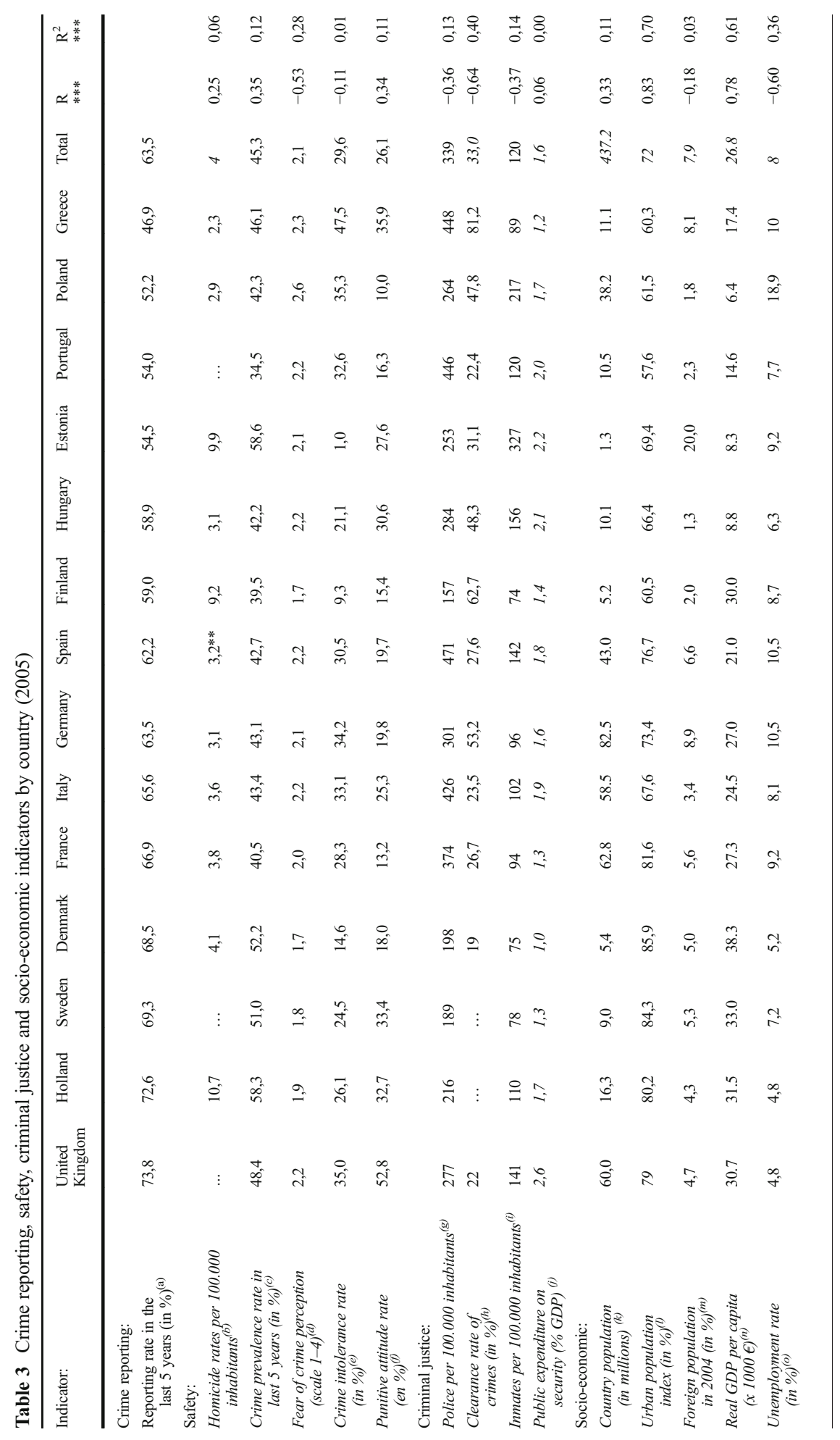




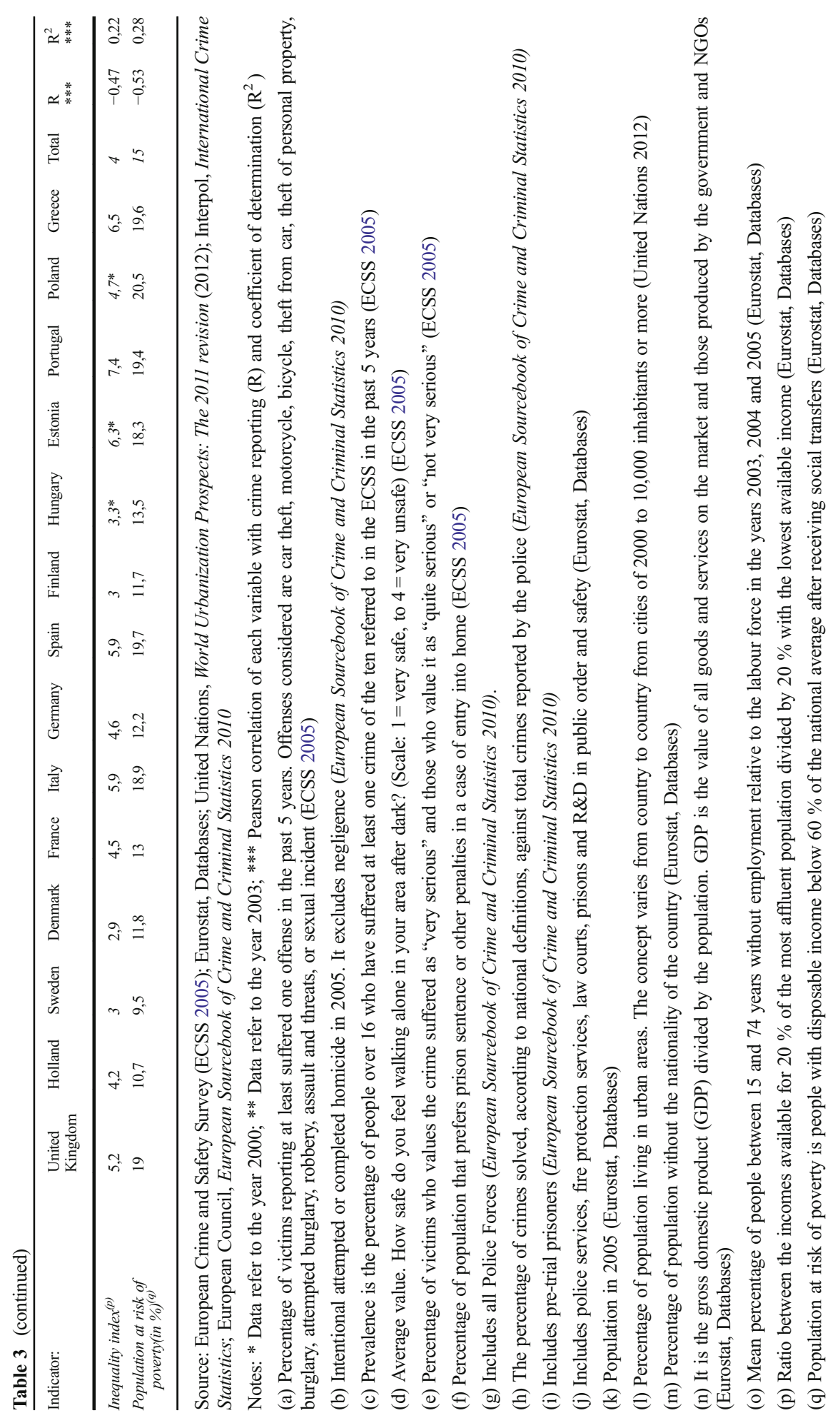


Table 4 Weight of European region in crime reporting (unadjusted and adjusted odds ratio and $95 \%$ confidence intervals)

\begin{tabular}{|c|c|c|c|c|}
\hline \multirow[t]{2}{*}{ European region: } & \multicolumn{2}{|c|}{ Unadjusted effect } & \multicolumn{2}{|c|}{ Adjusted effect ${ }^{(\mathrm{e})}$} \\
\hline & OR & Confidence interval & OR & Confidence interval \\
\hline Northern $^{(a)}$ & 1 & & 1 & \\
\hline Central $^{(b)}$ & 1.55 & $(1.43-1.68)$ & 1.13 & $(0.97-1.31)$ \\
\hline Southern $^{(\mathrm{c})}$ & 0.92 & $(0.84-1.01)$ & 0.51 & $(0.42-0.63)$ \\
\hline Eastern $^{(\mathrm{d})}$ & 0.60 & $(0.56-0.65)$ & 0.67 & $(0.53-0.85)$ \\
\hline Number of cases & 12,672 & & 6,965 & \\
\hline
\end{tabular}

Source: European Crime and Safety Survey (ECSS 2005). Brussels, Gallup Europa

Notes: $\mathrm{p}<0,05$

(a) Sweden, Denmark, Finland

(b) United Kingdom, France, Germany, Holland

(c) Spain, Portugal, Italy, Greece

(d) Estonia, Poland, Hungary

(e) Variables included in the adjusted model: type of crime suffered, use of weapons, crime severity, fear of crime, chances of suffering burglary, life satisfaction, drugs in the neighborhood perception, city size, police efficacy perception, age, gender, home size, religion, labour status, income, education, civil status, immigration, European region

region). The table shows the OR once adjusted for the rest of the variables in the model. In the case of criminal incidents, OR figures must be interpreted in relation to the chances of reporting any other offense. In order to identify the most relevant variables in terms of its explanatory capacity, a forward stepwise log regression method was used. By using this technique, we try to find the most parsimonious model identifying key variables in each region or country. This method leaves out variables that do not add information (represented by blank spaces in the columns).

If we consider indicators related to rational model theories, type of crime has a central role in explaining crime reporting (Laub 1981). However, we find important differences among regions. In northern countries, criminal incidents retain a high OR, while keeping the highest explanatory capacity (entrance order) in relation to other variables. The same can be said in relation to the central European countries. In southern countries the panorama changes dramatically. Crime incidents lose a lot of their explanatory capacity and also the OR is not as high as for central and northern regions. Eastern countries follow a distinctive behaviour. In general terms, criminal facts are important in terms of explaining crime reporting, but some incidents, especially related to vehicles and burglary, trigger a spectacular rise in the OR. Overall, incidents involving vehicles and homes (burglary) are the main drivers of crime reporting in all areas, albeit this effect is somewhat greater in the eastern European region. There is a discussion in the literature about what may explain this salience. Skogan (1984) argued that this effect could be related to the value of the stolen goods and insurance claims. Other authors affirm that this can hold at the individual level, but not so much at the national one (Goudriaan et al. 2004). Contact crimes, and especially sexual incidents, seem to play a negative role in reporting. Offence severity (as evaluated by the victim) is a highly relevant factor in crime reporting, especially in central and southern countries. The presence of weapons has certain salience in the central and northern European regions, but is not a significant factor in southern and eastern regions after adjusting. 


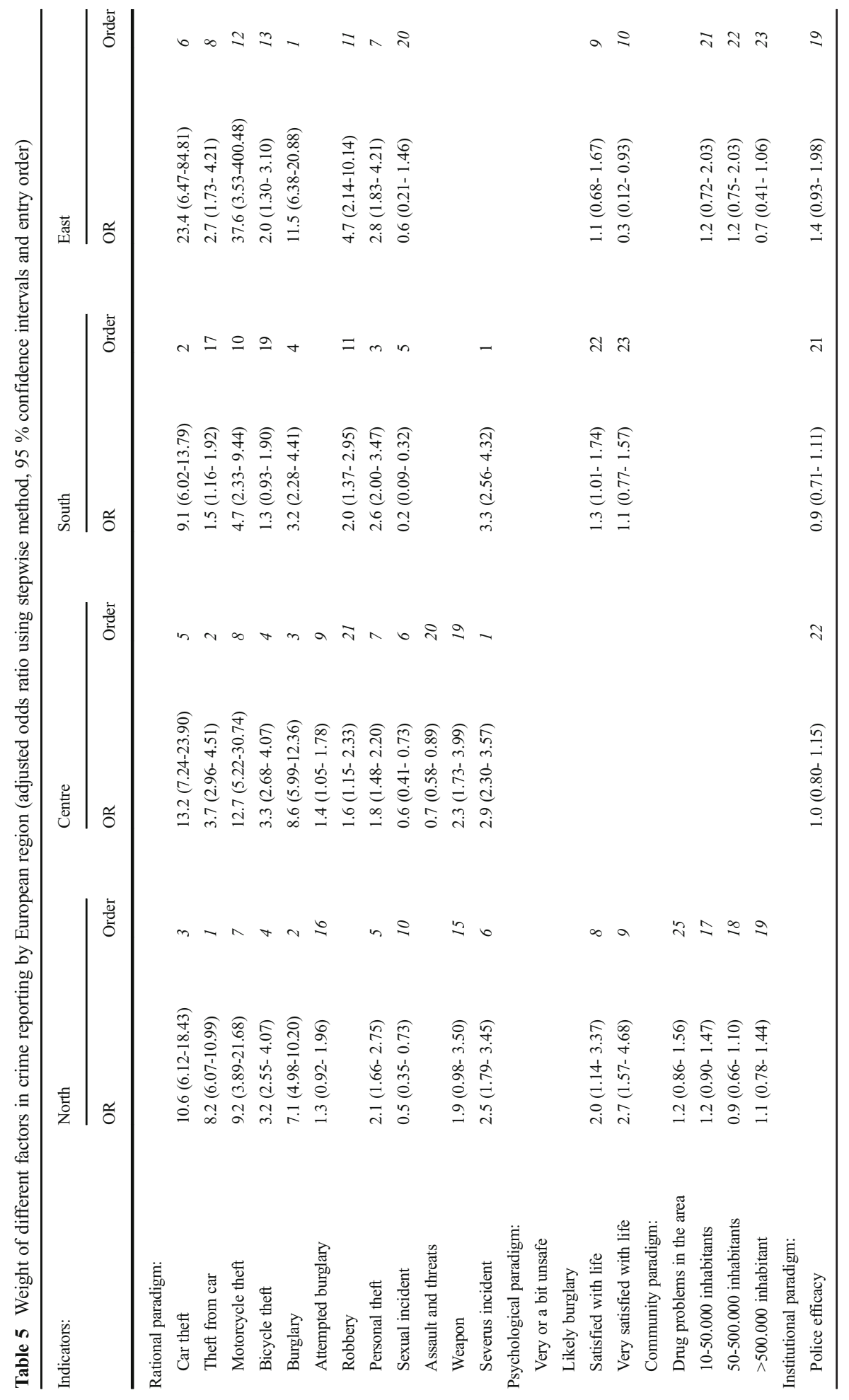




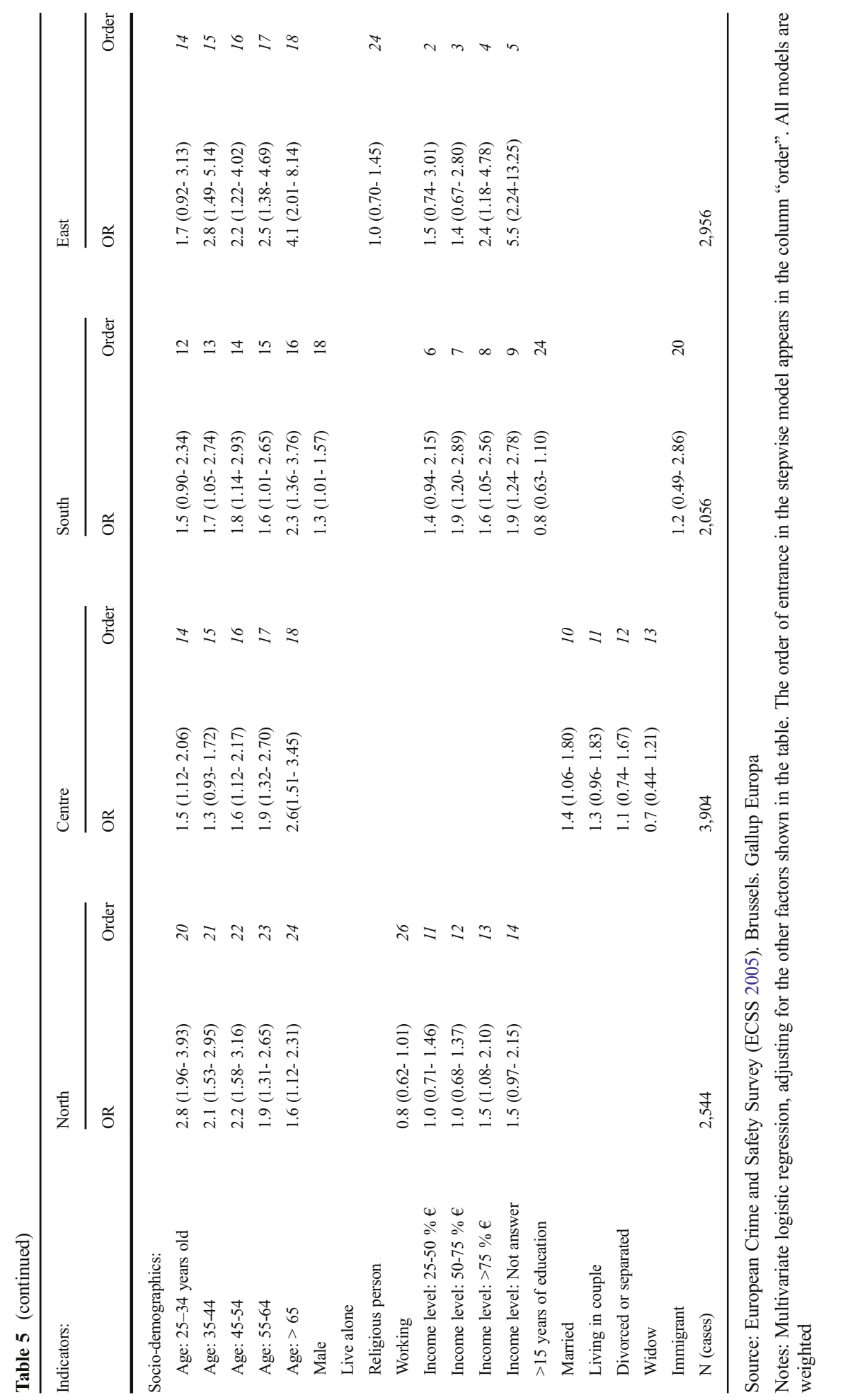


The indicators related to psychological factors have, overall, a moderate importance in explaining aggregate crime reporting. Most of them have low OR values and lose their significance or explanatory capacity when their effect is controlled for other variables. This is the case with fear of crime and perceived likelihood of someone stealing from your home. Conversely, life satisfaction has an impact in accounting for crime reporting. In the Northern region, this effect is clear and positive in terms of explaining OR and variance. People expressing higher life satisfaction levels are also greater crime reporters. This could be interpreted in terms of security being perceived as a dimension of quality of life and overall life satisfaction.

Challenging our expectations, socio-communitarian factors are not very influential in crime reporting at this macro-level. The presence of drugs in the neighbourhood as an indicator of social disorganization does not yield significant results in any region. City size, as an indicator of degree of urbanization, has a minor importance in northern and eastern European regions. One possible explanation for these results might be the scarce and poor quality of community and social indicators in the ECSS survey. The same can be argued in the case of institutional factors represented by perceived effectiveness of the police. Indeed, this variable only seems to have a discrete and positive relevance in the case of eastern countries. Estonia, Poland and Hungary express a low perception of police efficacy in ECSS surveys (EUCPN 2012). It would appear overall that, in this context, those who have more confidence in police effectiveness are more prone to report.

When socio-demographic factors are considered, some interesting results appear. Age, for example, is a significant, although modest, factor in the relationship between citizens and the police. In all areas, with the exception of northern regions, crime reporting increases with age. This trend is particularly strong (in OR terms) in the eastern region. In central and southern Europe, the chance of reporting crime also increases with age, although to a lesser extent. Interestingly, however, in northern Europe reporting to the police is greater among younger segments of the population and its positive effect is maintained throughout all life stages. At the same time, age has less explanatory capacity of crime reporting in the northern region than in the rest of regions. This may imply that age-based barriers to police access are fewer in northern countries than in other European areas.

Income is another significant socio-demographic factor. In eastern countries, income inequalities have much more importance in explaining crime reporting than in the other regions. This variable enters the stepwise model with a high priority, revealing its explanatory capacity. If we consider the OR, the highest income segment reports more often than the rest. In southern countries, this variable also retains a high explanatory capacity and shows also a socio-economic gradient in crime reporting. Income does not seem to be a significant variable for the central European region. In the case of northern Europe, the OR are close to the value of 1 , with an exception made of the highest income group indicating that high income level is associated to greater reporting rates. Taken as a whole, the above data point to that income is a relevant factor and income inequalities may be acting as a barrier to crime reporting in the eastern region and, to a lesser extent, in the southern region countries. In the adjusted model, marital status is fairly irrelevant as a factor in most European regions, although in central European countries being married could favour crime reporting. Being an immigrant does not show to have a significant impact on crime reporting. Finally other variables such as gender, religion, education, being employed and living alone are not significant variables in the model.

A bird's eye view of the results, point to some differences among regions in factors affecting crime reporting. The type of crime drives crime reporting in northern and central countries more than it is in south and east Europe (with the exception of vehicle-related crimes and burglary). Consequently, rational models fit the reality of the former better than they do the 
latter. In general, social inequalities have more impact on police reporting in southern and eastern Europe than in the North. It is also worth noting that in northern countries crime reporting is clearly associated with life satisfaction. Finally, the perception of police efficacy seems an important factor in eastern countries. These findings show that the theoretical frameworks used to understand crime reporting are not universal. Different factors affect different regions in different ways.

\section{Discussion of results and conclusions}

We have shown significant differences in crime reporting rates among European regions. Most available empirical research to date has been done at the micro-level, fairly incident centred, with a national scope and, when available, conducted in a limited range of countries. There is a lack of truly comparative studies. This research contributes to a better understanding of crime reporting by carrying out a comparative analysis that includes $14 \mathrm{EU}$ countries grouped up in regions, and adopting a multi-theoretical approach.

A key finding in our study is that crime reporting shows significant differences across countries and regions. Univariate logistic regression shows that that there are four regional patterns, approximately corresponding to European socio-economic areas (northern, central, eastern and southern countries). However, when controlling for all the variables in the model, two clear axes arise: northern-central and southern-eastern. In the latter, the likelihood of crime reporting is about half of the former. This suggests the existence of underlying factors.

A second key finding is that there are regional differences not only in reporting rates, but also in the weight of the different types of causal factors affecting crime reporting. Crime reporting in northern and central countries is more influenced by the type of crime than in southern and eastern Europe. Conversely, in general, social inequalities have more impact on police reporting in southern and eastern Europe than in other regions. Income, for example, is a key factor in eastern and, to a lesser degree, southern Europe, and age is similar. The type of crime suffered (rather than its severity) and social inequalities are the two variables that most discriminate between reporting in these two macro-areas.

Both findings have theoretical and methodological implications. From a theoretical point of view, no single paradigm can satisfactory explain differences in crime reporting in crossnational comparative research. The results obtained show that, although they retain quite explanatory capacity, rational models cannot fully explain crime reporting in southern Europe, where socio-demographic factors are more relevant. Psychological models have less explanatory relevance in comparative research, but they seem to work better depending on the specific indicator used. While fear of crime is not relevant in this international analysis, life satisfaction is a prominent factor in some northern countries, particularly Sweden. In our research, institutional factors were represented only by perception of police efficacy. This variable seems to be more relevant in extreme cases where there is either a remarkable positive attitude towards the police, as happens in particular northern countries as Finland and Denmark, or a more critical perception of their efficacy, as in eastern countries. Sociocommunitarian indicators, contrary to our initial expectations, do not prove to be very relevant, but the indicators were very poor and the ECSS do not provide indicators in social disorganization, social capital, interpersonal trust, or other theoretically relevant areas. Despite this limitation, community drug problems have a light effect on the northern region. Finally, two socio-demographic factors, particularly in south and east countries, are revealed to be 
important in comparative research: income and age. This highlights the importance of considering social inequalities as a barrier to accessing police services.

The fact that we lack an appropriate theoretical framework for explaining international crime reporting also raises some methodological questions. There is some evidence that institutional and socio-communitarian frameworks could contribute to the issue, and his clue needs to be explored further. However, international crime surveys do not include indicators of social disorder, community cohesion, social networks or social capital, among others. Some of them are hard to capture by survey methods. So, other data sources need to be combined. Good research at the community level also needs a focus on local dynamics. Doing more research at this level may be inspiring. Institutional perspectives must explore further the effect on crime reporting of the availability services for victims, or the type of response they receive. A better understanding of the relationship between offer and demand of police services is needed.

In conclusion, and confirming our first hypothesis, the results highlight the diversity and complexity of the factors that explain crime reporting at the country level. There is a considerable diversity in the factors explaining national realities. At the same time, however, and validating our second hypothesis, there are two main macro-factors that are able to discriminate between regions, painting a picture of two large blocks of countries. These macro-factors are type of crime for central and northern countries and some sociodemographic variables for southern and eastern European countries. This research has two main limitations. The first being its descriptive and exploratory character. It does not explain (and does not try to do it) crime-reporting differences at the national level. At present, we lack the necessary theoretical framework. An explicative focus also implies a more disaggregate analysis of factors affecting different types of crime. Because the numerical dominance of property crime in total crime, our model and inferences reflect more property than violent/ personal crime. A second limitation is imposed by the variables included in the ECSS. In this respect, there is a lack, or inadequacy, of institutional and socio-communitarian indicators in the survey data. In order to extend our understanding of cross-national crime reporting, future research should be more focused on aggregate factors, and more innovative in methods.

\section{References}

Anderson, E. (1999). Code of the street: decency, violence, and the moral life of the inner city. New York: Norton. Baumer, E. P. (2002). Neighborhood disadvantage and police notification by victims of violence. Criminology, 40, 579-617.

Baumer, E. P., \& Lauritsen, J. L. (2010). Reporting crime to the police 1973-2005: a multivariate analysis of the long term trends in the national crime survey (NCS) and national victimization survey (NCVS). Criminology, 48(1), 131-185.

Bennet, R., \& Weigand, R. B. (1994). Observations on crime reporting in a developing nation. Criminology, 135, $135-148$.

Bercal, T. E. (1970). Calls for police assistance: consumer demands for governmental service. American Behavioral Scientist, 13(5/6), 681 .

Black, D. (1976). The Behavior of Law. New York: Academic Press.

Bouten, E., Goudriaan H. and Nieuwbeerta P. (2003). Victimación delictiva en 17 países industrializados. Revista Española de Criminología 102(3).

Carcach, C. (1997). Reporting Crime to the Police. Trends \& issues in crime and criminal justice 68. Australian Institute of Criminology.

Conaway, M. R., \& Lohr, S. L. (1994). A longitudinal analysis of factors associated with reporting violent crime to the police. Journal of Quantitative Criminology, 10(1), 23-39. 
European Crime Prevention Network EUCPN (2012) Public opinion and policy on crime prevention in Europe. European Crime Prevention Monitor 2012/2.

Felson, R. B., Messner, S. F., \& Hoskin, A. (1999). The victim-ofender relationship and calling the police in assaults. Criminology, 37(4), 931.

Felson, R. B., Messner, S. F., \& Hoskin, A. (2002). Reasons for reporting and No reporting violence to the police. Criminology, 40(3), 617.

Fisher, B. S., Daigle, L. E., Cullen, F. T., \& Turner, M. G. (2003). Reporting sexual victimization to the police and others. Results from a national-level study of college women. Criminal Justice and Behavior, 30(1), 638.

Fishman, G. (1979). Patterns of victimisation and notification. British Journal of Criminology, 19, $146-57$.

Gottfredson, M. R., \& Hinderland, J. (1979). A study of the behavior of law. American Sociological Review, 44, $3-18$.

Goudriaan, H., Lynch, J. P., \& Nieuwbeerta, P. (2004). Reporting to the police in western nations: a theoretical analysis of the effects of social context. Justice Quarterly, 21(4), 933-969.

Goudriaan, H., Nieuwbeeta, J. P., \& Wittebrood, K. (2005). Overzicht van onderzoek naar determinanten van aangifte doen bij de politie. Theorieën, empirische bevindingen, tekortkomingen en aanbevelingen [overview of research into determinants of reporting to the police. Theories, empirical findings, shortcomings, and recommendations]. Tijdschrift voor Veiligheid en Veiligheidszorg, 4(1), 27-48.

Green, G. (1981). Citizen reporting of crime to the police. An analysis of common theft and assault. $\mathrm{PhD}$ Dissertation. University of Pennsylvania.

Greenberg, M. S., \& Ruback, R. B. (1992). After the crime: victim decision making. New York: Plenum.

Jaehnig, W. B., Weaver, D. H., \& Fico, F. (1981). Reporting crime and fearing crime in 3 communities. Journal of Communication, 31(1), 88-96.

Kääriäinen, J., \& Sirén, R. (2011). Trust in the police, generalized trust and reporting crime. European Journal of Criminology, 8(1), 65-81.

Kury, H., Teske, R. H. C., \& Würger, M. (1999). Reporting of crime to the police in the federal republic of Germany: a comparison of the old and the new lands. Justice Quarterly, 16, 123-51.

Laub, J. (1981). Ecological considerations in vicitms reporting to the police. Journal of Criminal Justice, 19, 419-430.

Mayhew, P. (1993). Reporting crime to the police: the contribution of victimization surveys. In W. Bilsky, C. Pfeiffer, \& P. Wetzels (Eds.), Fear of crime and criminal victimization (pp. 141-57). Stuttgart: Enke.

Reyns, B. W., \& Englebrecht, C. M. (2010). The stalking victim's decision to contact the police: a test of gottfredson and Gottfredson's theory of criminal justice decision making. Journal of Criminal Justice, 38, 998-1005.

Reiss, A. J. (1971). The police and the public (p. 228). New Haven: Yale University Press.

Ruback, R. B., Ménard, K. S., Outlaw, M. S., \& Shaffer, J. N. (1999). Normative advice to campus crime victims: effects of gender, age, and alcohol. Violence and Victims, 14, 381-396.

Sabaté, J. (2005). L'enquesta de victimització de Barcelona y de l'Àrea Metropolitana, vint-and-dos anys. Una proposta d'anàlisi de la seguretat urbana des de l'administració local (p. 247). Barcelona: Institut dEstudis Regionals i Metropolitans de Barcelona.

Sampson, R. J., Raudenbush, S. W., \& Earls, F. (1997). Neighborhoods and violent crime: a multilevel study of collective efficacy. Science, 227, 918-24.

Schnebly, S. M. (2008). The influence of community-oriented policing on crime-reporting behavior. Justice Quarterly, 25(2), 223-51.

Shaw, C. R., \& McKay, H. D. (1942). (1969) Juvenile delinquency and urban areas (revised edition). Chicago: University of Chicago Press.

Sherman, L. W. (1993). Defiance, deterrence, and irrelevance: a theory of the criminal sanction. Journal of Research in Crime and Delinquency, 30, 381-473.

Skogan, W. G. (1976). Citizen reporting of crime: some national panel data. Criminology, 13, 535-549.

Skogan, W. G. (1978). Citizen satisfaction with police services: individual and contextual effects. Policy Studies Journal, 7, 469.

Skogan, W. G. (1981). Issues in the measurement of victimization. Whasington DC: US Department of Justice. Bureau of Statistics.

Skogan, W. G. (1984). Reporting crimes to the police. Status of the world research. Journal of Research on Crime and Delinquency, 21(2), 113-137.

Soares, R. R. (2004a). Development, crime, and punishment: accounting for the international differences in crime rates. Journal of Development Economics, 73(1), 155-84

Soares, R. R. (2004b). Crime reporting as a measure of institutional development. Economic Development and Cultural Change, 52(4), 851-871. 
Sparks, R. F., Genn, H. G., \& Dodd, D. J. (1977). Surveying victims: a study of the measurement of criminal victimization, perceptions of crime, and attitudes to criminal justice. New York: Wiley.

Tarling, R., \& Morris, K. (2010). Reporting crime to the police. Bristish Journal of Criminology, 50, 474-490.

Thomé, H., \& Torrente, D. (2003). Cultura de la seguridad ciudadana en España (p. 115). Madrid: Centro de Investigaciones Sociológicas.

Tolsma, J., Blaauw, J., \& Grotenhuis, M. T. (2012). When do people report crime to the police? results from a factorial survey design in the Netherlands. Journal of Experimental Criminology, 8(2), 117-34.

Torrente, D. (2001). Desviación y delito (p. 323). Madrid: Alianza Universidad.

Van Dijk, J. J. M. (2015). The case for survey-based comparative measures of crime. European Journal of Criminology, 12(4), 437-456.

Van Dijk, J. J. M., \& Mayhew, P. (1992). Criminal victimization in the industrialized world: Key findings of the 1989 and 1992 international crime surveys. The Hague: Ministry of Justice, Department of Crime Prevention.

Van Dijk, J. J. M., \& Steinmetz, C. (1980). The burden of crime on Dutch society 1973-79. Den Hague: Research and Documentation Centre. Ministry of Justice of Netherlands.

Van Dijk, J. J. M., Manchin, R., Van Kesteren, J., Nevala, S., \& Hideg, G. (2005). The Burden of Crime in the EU. Research Report: A Comparative Analysis of the European Crime and Safety Survey (ECSS 2005)

Van Dijk, J. J. M., Manchin, R., Van Kesteren, J., \& Smit, P. (2007). Criminal victimization in international perspective. Key findings from the 2004-2005 ICVS and EU ICS. Ministry of Justice of Netherlands

Vélez, M. B. (2001). The role of public social control in urban neighborhoods: a multilevel analysis of victimization risk. Criminology, 39, 837-64.

Waller, I., \& Okihiro, N. (1978). Burglary: the victim and the public. Toronto: University of Toronto Press. 